\title{
Consensus document for invasive coronary physiologic assessment in Asia-Pacific countries
}

Hak Seung Lee ${ }^{1}$, Joo Myung Lee ${ }^{2}$, Chang-Wook Nam³ ${ }^{3}$ Eun-Seok Shin ${ }^{4}$, Joon-Hyung Doh ${ }^{5}$, Neng Dai ${ }^{6}$, Martin K.C. Ng$^{7}$, Andy S.C. Yong ${ }^{8}$, Damras Tresukosol, Ajit S. Mullasari ${ }^{10}$, Rony Mathew ${ }^{11}$, Praveen Chandra ${ }^{12}$, Kuang-Te Wang ${ }^{13}$, Yundai Chen ${ }^{14}$, Jiyan Chen ${ }^{15}$, Kai-Hang Yiu ${ }^{16}$, Nils P. Johnson ${ }^{17}$, Bon-Kwon Koo ${ }^{1}$

${ }^{1}$ Department of Internal Medicine and Cardiovascular Center,

Seoul National University Hospital, Seoul, Republic of Korea

${ }^{2}$ Division of Cardiology, Department of Internal Medicine, Heart Vascular Stroke Institute, Samsung Medical Center, Sungkyunkwan University School of Medicine, Seoul, Republic of Korea ${ }^{3}$ Department of Medicine, Keimyung University Dongsan Medical Center, Daegu, Republic of Korea ${ }^{4}$ Department of Cardiology, Ulsan University Hospital, University of Ulsan College of Medicine, Korea

${ }^{5}$ Department of Medicine, Inje University Ilsan Paik Hospital, Goyang, Korea

${ }^{6}$ Department of Cardiology, Shanghai Institute of Cardiovascular Disease,

Zhongshan Hospital, Fudan University, Shanghai, China

${ }^{7}$ Department of Cardiology, Royal Prince Alfred Hospital, Camperdown, Australia

${ }^{8}$ Department of Cardiology, Concord Hospital, Sydney, Australia

${ }^{9}$ Division of Cardiology, Siriraj Hospital, Mahidol University, Bangkok, Thailand

${ }^{10}$ Institute of Cardiovascular Diseases, The Madras Medical Mission, Chennai, India

${ }^{11}$ Lisie Hospital, Kochi, Kerala, India

${ }^{12}$ Medanta, Gurgaon, India

${ }^{13}$ Division of Cardiology, Department of Internal Medicine, Mackay Memorial Hospital, Taitung Branch, Taiwan

${ }^{14}$ Department of Cardiology, Chinese PLA General Hospital, Beijing, China

${ }^{15}$ Guangdong Provincial Key Laboratory of Coronary Heart Disease Prevention, Guangdong Cardiovascular Institute, Guangdong General Hospital, Guangdong Academy of Medical Sciences, Guangzhou, China

${ }^{16}$ Division of Cardiology, Department of Medicine, University of Hong Kong, Queen Mary Hospital, Hong Kong, China

${ }^{17}$ McGovern Medical School at UTHealth and Memorial Hermann Hospital, Houston, Texas, United States

\begin{abstract}
Background: Currently, invasive physiologic assessment such as fractional flow reserve is widely used worldwide with different adoption rates around the globe. Patient characteristics and physician preferences often differ in the Asia-Pacific (APAC) region with respect to treatment strategy, techniques, lesion complexity, access to coronary physiology and imaging devices, as well as patient management. Thus, there is a need to construct a consensus document on recommendations for use of physiology-guided percutaneous coronary intervention (PCI) in APAC populations. This document serves as an overview of recommendations describing the best practices for APAC populations to achieve more consistent and optimal clinical outcomes.
\end{abstract}

Address for correspondence:

Prof. Bon-Kwon Koo, MD, PhD, Seoul National University College of Medicine, 101 Daehang-ro, Chongno-gu, Seoul, 110-744, Korea, tel: 82-2-2072-2062 (office), 82-2-2072-2677 (cath lab), fax: 82-2-3675-0805, e-mail: bkkoo@snu.ac.kr

Nils P. Johnson, MD, MS, Weatherhead PET Center, McGovern Medical, School at UTHealth, 6431 Fannin Street, Room, MSB 4.256, Houston, Texas 77030, United States, e-mail: nils.johnson@uth.tmc.edu 
Methods and Results: A comprehensive multiple-choice questionnaire was provided to 20 interventional cardiologists from 10 countries in the APAC region. Clinical evidence, tips and techniques, and clinical situations for the use of physiology-guided PCI in APAC were reviewed and used to propose key recommendations. There are suggestions to continue to develop evidence for lesion and patient types that will benefit from physiology, develop directions for future research in health economics and local data, develop appropriate use criteria in different countries, and emphasize the importance of education of all stakeholders. A consensus recommendation to enhance the penetration of invasive physiology-based therapy was to adopt the 5 E approach: Evidence, Education, Expand hardware, Economics and Expert consensus.

Conclusions: This consensus document and recommendations support interventional fellows and cardiologists, hospital administrators, patients, and medical device companies to build confidence and encourage wider implementation of invasive coronary physiology-guided therapy in the APAC region. (Cardiol J 2019; 26, 3: 215-225)

Key words: coronary physiology, invasive physiologic assessment, quality improvement

\section{Introduction}

Coronary angiography can no longer be considered a gold standard for determining the functional significance of coronary stenosis given its known limitations including eccentric plaque morphology, frequent lack of a normal reference segment, visual overestimation, and inter-observer variability [1-3]. As a consequence of these limitations, intracoronary physiology assessment and imaging have been developed to provide superior diagnostic information for coronary stenotic lesions $[4,5]$. Fractional flow reserve (FFR) was developed to define the functional significance of a coronary stenosis in a cardiac catheterization laboratory. In addition, resting pressure-derived physiologic indices have also been developed and used in daily clinical practice [6]. However, their penetration rate in the Asia-Pacific (APAC) region is highly variable and low in general.

This consensus statement for the APAC region briefly reviews important clinical studies to develop a practical message regarding when and how to use coronary physiology, and aims to promote physician education at different stages of adopting physiologic assessment into clinical practice.

\section{Methods}

This paper is based on a meeting sponsored by Abbott Vascular in April 2018 of 20 interventional cardiologists from 10 countries (Australia, China, India, Japan, Korea, Singapore, Taiwan and Thailand) with significant experience in performing physiology-guided percutaneous coronary intervention (PCI). The goal of the meeting was to understand invasive physiology practice across the APAC region and to develop a consensus statement. A pre-meeting survey was followed by an interactive discussion. The participants included high-volume interventional cardiologists with extensive experience:

- at least $300 \mathrm{PCIs}$ performed per year;

- $\sim 2 / 3^{\text {rd }}$ performing $6-10$ physiology procedures per month; $1 / 3^{\text {rd }}$ performing more than 10 physiology procedures per month;

- $2 / 3^{\text {rd }}$ administering intravenous hyperemia during physiology-guided PCI;

- $2 / 3^{\text {rd }}$ considering physiology during ST-segment elevation myocardial infarction (STEMI).

Clinical evidence, tips and techniques, and clinical situations for the use of physiology-guided $\mathrm{PCI}$ in APAC were reviewed and used to propose key recommendations. Against the backdrop of the available clinical evidence and the physicians' personal experience, the group discussed multiple issues pertaining to physiology-guided PCI.

- Lesion/patient subsets recommended and not recommended for invasive physiologic assessment;

- Current evidence gaps and areas for further research;

- Trends of differential utilization of coronary physiologic assessment;

- Learning curve and barriers to routine adoption of physiologic assessment;

- Impact of appropriate use criteria on physiologic assessment adoption in APAC countries;

- Resting physiology:

- clinical evidence about resting flow,

- benefits and limitations of adopting rest- 
ing physiologic assessment into daily practice,

- role of non-hyperaemic resting ratios such as resting full-cycle ratio (RFR) or diastolic pressure ratio (dPR) to drive the adoption of invasive physiologic assessment;

- Technologies to assess microvascular disease:

- current role of coronary flow reserve (CFR) and index of microcirculatory resistance (IMR) in clinical practice, based on evidence,

- evidence gaps for CFR and IMR,

- relevance of CFR and IMR as a mainstream clinical tool,

- role of CFR in clinical practice: current and future.

\section{Results and discussion}

Key findings of the pre-meeting survey are as follows:

- FFR was the most common physiology index, followed by IMR and instantaneous wave-free ratio (iFR);

- Common criteria for considering physiology assessment in clinical practice were intermediate or ambiguous lesions and stenosis of bifurcation lesions, in-stent restenosis, left main lesions, multi-vessel disease, and STEMI. However, all agreed that stenosis severity alone should not be the sole gatekeeper for invasive physiologic assessment;

- Adenosine was the hyperaemic agent of choice based on its availability. However, intracoronary nicorandil was also considered as an alternative agent based on equivalent hyperaemic efficacy and significantly lower procedural time and patient discomfort $[7,8]$;

- Cost and additional time needed to conduct the procedure were identified as the main factors preventing the routine use of physiologic assessment. Multiple factors were identified as potentially being able to increase physiology-guided PCI. These are separately discussed as recommendations of the group;

- Use of post-PCI physiology still remains an emerging area, with a majority of interventional cardiologists using it in $<25 \%$ of the total number of physiology procedures;

- Despite the latest evidence including theoretical support of reliability in FFR value and prognostic benefit of an FFR-guided strategy for non-culprit lesions during STEMI presen- tation, more than $50 \%$ of respondents do not use it routinely;

- The use of CFR and IMR as a physiological tool remains modest with only limited operators understanding its potential. Availability of more clinical evidence, better software, and a simplified clinical protocol may support adoption of CFR and IMR;

- iFR, one of several pressure-derived physiologic indices that avoids hyperaemia, has few users in the APAC regions as a routine procedure. Some factors supporting iFR in practice include fewer side effects compared with FFR, faster procedural time and lower cost;

- Education of all stakeholders (consultants, technicians, nursing staff, patients, referring physicians, and insurers) was identified as a key step and is discussed separately in the recommendations section.

Numerous factors influence treatment decision patterns and differ among countries. Physicians will always rely on a combination of their knowledge, experience, and the guidelines to shape a therapeutic strategy. The following are a summary of issues discussed during the meeting.

\section{Current guidelines and clinical evidence}

The latest update of the American College of Cardiology/American Heart Association (ACC/ /AHA) Guideline for the Diagnosis and Management of Patients with Stable Ischemic Heart Disease states: "It has been suggested in several studies that a PCI (percutaneous coronary intervention) strategy guided by FFR may be superior to a strategy guided by angiography alone." [9]. In the absence of non-invasive proof of ischemia, FFR performed in a coronary stenosis with a $40-90 \%$ diameter reduction was given a "class I recommendation" and "level of evidence A" in the guidelines for coronary revascularization published by the European Society of Cardiology (ESC) in 2019 (Table 1) [10].

Based on the results of several randomized, prospective clinical studies and registries evaluating physiology-guided PCI in many thousands of patients, the clinical relevance of FFR is well established and documented (Fig. 1). Even when non-invasive proof of ischemia is available, FFR measurements often change clinical judgment regarding the need to revascularize a given coronary artery stenosis [11]. Table 2 shows the summary of studies which investigated the changes in 
Table 1. Recommendations on functional testing and for lesion assessment -2018 European Society of Cardiology/European Association for Cardio-Thoracic Surgery (ESC/EACTS) guidelines on myocardial revascularization.

\begin{tabular}{lcc}
\hline Recommendations & Class of recommendation & Level of evidence \\
\hline $\begin{array}{l}\text { When evidence of ischaemia is not available, FFR or iFR } \\
\text { are recommended to assess the hemodynamic relevance } \\
\text { of intermediate-grade stenosis }\end{array}$ & $\mathrm{A}$ \\
$\begin{array}{l}\text { FFR-guided PCl should be considered in patients with } \\
\text { multivessel disease undergoing PCl }\end{array}$ & Ila & B \\
\hline
\end{tabular}

FFR — fractional flow reserve; iFR — instantaneous wave free ratio; $\mathrm{PCl}$ - percutaneous coronary intervention

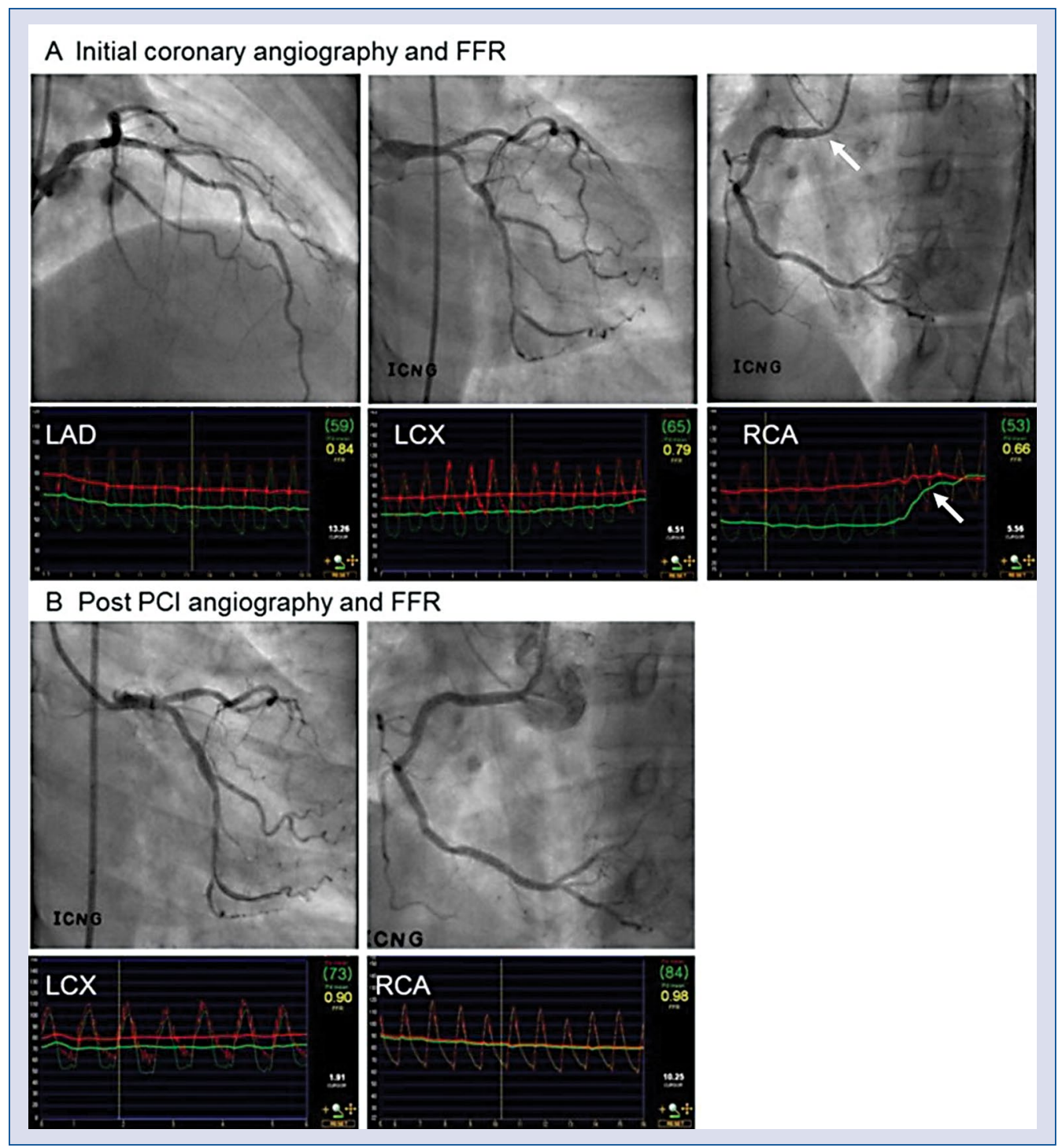

Figure 1. A case of physiology guided percutaneous coronary intervention (PCI). A. A patient showed angiographically, two vessel disease with stenosis in left anterior descending artery (LAD) and left circumflex artery (LCX). However, fractional flow reserve (FFR) in LAD, LCX and right coronary artery (RCA) was $0.84,0.79$, and 0.66 , respectively. In contrast to angiographic assessment, physiologic assessment showed that the targets of revascularization were LCX and RCA, not LAD. In RCA, significant pressure step-up occurred the ostium (arrow); B. PCI was performed for proximal LCX and RCA lesions and post PCI FFR at LCX and RCA was 0.90 and 0.98 , respectively. 
Table 2. Changes in management strategy after invasive physiologic assessment.

\begin{tabular}{|c|c|c|c|}
\hline Trial [year] & Subjects & Pressure wire assessment & Change in management strategy \\
\hline $\begin{array}{l}\text { DEFINE REAL } \\
\text { (2018) [12] }\end{array}$ & $\begin{array}{l}\text { Multivessel } \\
\text { disease }\end{array}$ & $\begin{array}{c}\text { FFR and/or iFR } \\
\text { Intermediate lesions }\end{array}$ & $26.9 \%$ (130 of 484 patients) \\
\hline $\begin{array}{l}\text { POST-IT } \\
(2016)[13]\end{array}$ & FFR in $\geq 1$ vessel & $\begin{array}{c}\text { FFR } \\
\text { Operator's discretion }\end{array}$ & $44.2 \%$ (406 of 918 patients) \\
\hline $\begin{array}{l}\text { FAMOUS-NSTEMI } \\
(2015) \text { [14] }\end{array}$ & NSTEMI & $\begin{array}{c}\text { FFR } \\
\text { All lesions with } \\
\geq 30 \% \text { stenosis }\end{array}$ & $21.6 \%$ (38 of 176 patients) \\
\hline $\begin{array}{l}\text { CVIT-DEFER } \\
\text { (2015) [15] }\end{array}$ & FFR in $\geq 1$ vessel & $\begin{array}{c}\text { FFR } \\
\text { Intermediate lesions }\end{array}$ & $39.0 \%$ (1205 of 3093 patients) \\
\hline $\begin{array}{l}\text { R3F } \\
(2014)[16]\end{array}$ & $\begin{array}{l}\text { Ambiguous } \\
\text { stenosis }+\end{array}$ & $\begin{array}{c}\text { FFR } \\
\text { Angiographically } \\
35 \% \text { to } 65 \% \text { stenosis }\end{array}$ & $43.2 \%$ (464 of 1,075 patients) \\
\hline $\begin{array}{l}\text { RIPCORD } \\
(2014)[17]\end{array}$ & Stable chest pain & $\begin{array}{c}\text { FFR } \\
\text { All coronary arteries } \\
\geq 2.25 \mathrm{~mm}\end{array}$ & $26.5 \%$ (53 of 200 patients) \\
\hline
\end{tabular}

FFR — fractional flow reserve; iFR — instantaneous wave free ratio; NSTEMI — non-ST-segment elevation myocardial infarction; PW — pressure wire

management strategy after invasive physiologic assessment [12-17].

Key findings from previous pivotal FFR trials can be summarised as follows:

- DEFER trial [18] showed that FFR-based deferral of revascularization for a functionally insignificant stenosis was safe in up to 15 years of follow-up, and revascularization of these lesions could not have improved the prognosis. The DEFER-DES trial [19], which was conducted in the era of drug-eluting stents, also showed similar results to the DEFER trial;

- FAME trial [20] showed that an FFR-guided strategy reduced the risk of major adverse cardiac events compared with an angiographyguided strategy, with less use of stents per patient, contrast media, and medical cost. Recently published 5 -year follow-up data showed no late catch-up of events in the FFR-guided group;

- FAME II trial [21] clearly showed that in patients with stable coronary artery disease (CAD), an initial FFR-guided PCI strategy resulted in a sustained clinical benefit compared with medical therapy alone using a composite primary endpoint of death, myocardial infarction, or urgent revascularization at 5 years. Patients without hemodynamically significant stenosis had a favourable long-term outcome with medical therapy alone;

- COMPARE ACUTE [22]: In patients with STEMI and multi-vessel disease who underwent primary PCI of an infarct-related artery, the addition of immediate FFR-guided com- plete revascularization of non-infarct-related arteries in the acute setting resulted in the risk of a composite cardiovascular outcome that was lower than the risk among those who were treated for the infarct-related artery only. This reduction was mainly driven by the decreased need for subsequent revascularization;

- DANAMI-3-PRIMULTI [23]: In patients with STEMI and multi-vessel disease who underwent primary PCI of an infarct-related artery, the addition of staged FFR-guided complete revascularization of non-infarct-related arteries (median interval 2 days) resulted in the risk of a composite cardiovascular outcome that was lower than the risk among those who were treated for an infarct-related artery only. This reduction was mainly driven by a decreased need for subsequent revascularization [9].

\section{Clinical application of resting physiologic indices}

Recently, iFR was introduced as an alternative to FFR that does not require hyperaemia (Fig. 2). Two large randomized trials, the DEFINE-FLAIR [24] and the iFR-SWEDEHEART trial [25], claimed non-inferiority of iFR compared with FFR but did not focus on the $20 \%$ of lesions with discordant treatment decisions between iFR and FFR. In studies by Lee et al. [26-28], both iFR and FFR changed significantly according to different anatomical and hemodynamic stenosis severity. However, FFR showed more sensitive changes to the severity of a stenosis than iFR. Currently, European guidelines 


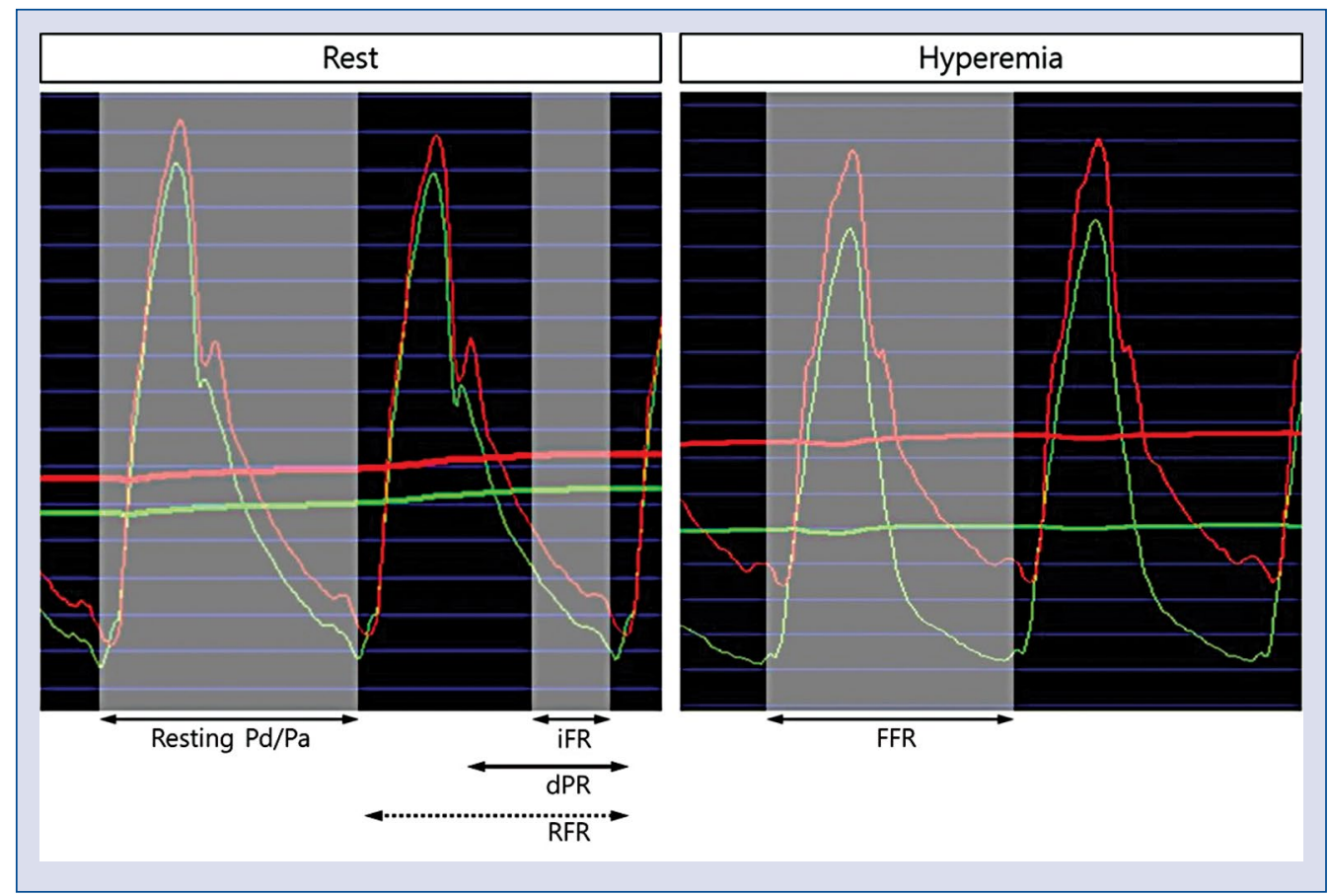

Figure 2. Resting and hyperemic pressure-derived invasive physiologic indices; abbreviations - see text.

consider iFR as largely equivalent to FFR [9]. Integration of both resting and hyperaemic physiologic indices may provide better information for clinical decision-making as recent studies suggested that the discordance between iFR and FFR might have clinical implications [29-31]. In addition to iFR, resting physiologic indices such as $\mathrm{APR}$ or diastolic hyperemia-free ratio and RFR have been introduced and showed equivalent diagnostic performance to iFR [32, 33]. As FFR is the most commonly used invasive physiologic index in the APAC region, further discussion is needed to provide a guide for use of resting indices in daily practice.

\section{Role of microvascular assessment}

Since the coronary artery system has three components (epicardial coronary arteries, arterioles, and capillaries), myocardial ischemia can occur within any one of these levels. Although the microvascular system cannot be visualized by invasive coronary angiography, its function can be evaluated by invasive physiologic assessment. It is well-known that the presence of microvascular dysfunction is associated with a poor prognosis in patients who do not have significant epicardial CAD (Fig. 3). IMR is a specific index for microvascular status and can be measured by a thermodilution technique. CFR represents the microvascular status when there is no significant epicardial disease and can be measured using a Doppler wire or a pressure/temperature-sensor guide wire. The international IMR registry with 1,096 Asian and Western patients (1,452 vessels) found that there was no correlation between IMR and FFR values $(r=0.01 ; p=0.62)$ and between IMR and angiographic percent diameter stenosis $(\mathrm{r}=-0.03$; $\mathrm{p}=0.25$ ) [34]. The optimal cut off value in patients with stable CAD was 25 (arbitrary units). In a Korean study which investigated the prognosis of patients according to CFR and IMR levels, the presence of low CFR in conjunction with high IMR was the most powerful independent predictor for clinical events among patients with high FFR [35]. These results suggest that the use of invasive physiologic assessment for microvascular disease should be encouraged, as it can help identify patients at high risk for future cardiovascular events among those with high FFR. In order for microvascular assessment to be used more, the logistic and reimbursement issues need to be resolved, along with more education about microvascular disease and techniques for its assessment.

\section{Global physiology practice}

Invasive coronary physiology is used worldwide now, with the first instance of resting coronary 


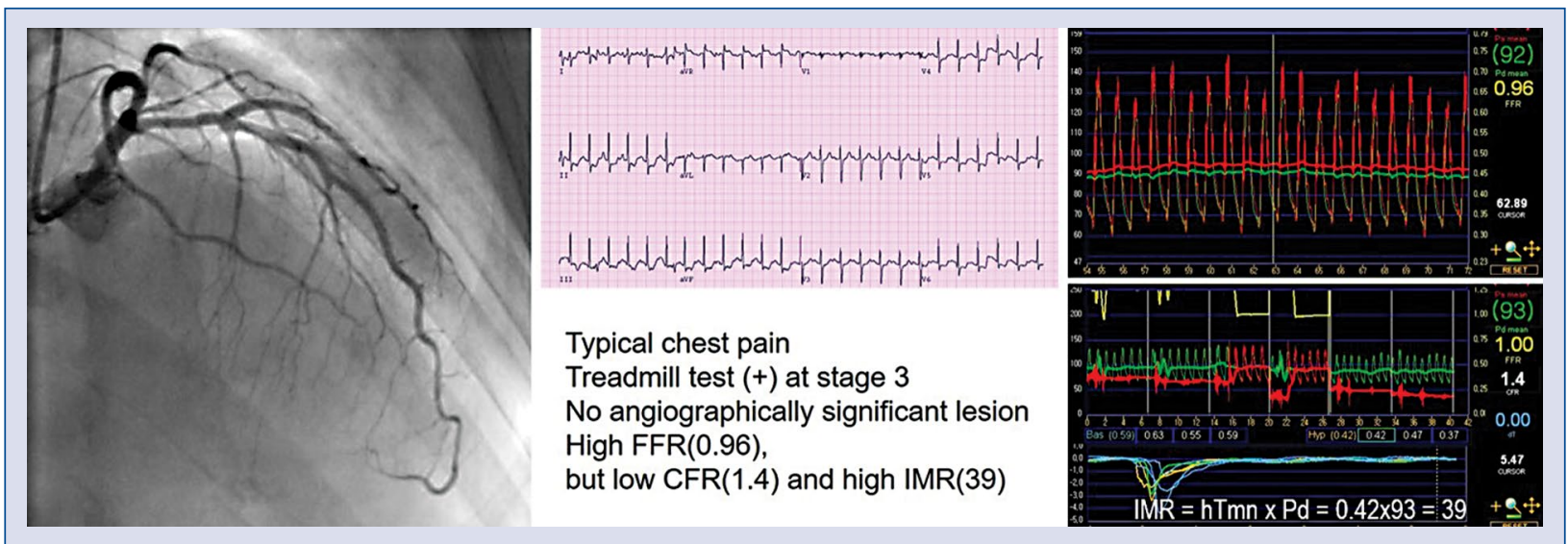

Figure 3. A case of microvascular disease assessed by coronary flow reserve (CFR) and index of microcirculatory resistance (IMR). The patient presented with typical chest pain on exertion and a positive exercise stress test. Coronary angiography showed no obstructive epicardial coronary artery disease and fractional flow reserve (FFR) was insignificant in the left anterior descending artery (LAD). However, CFR was low and IMR was high in LAD, suggesting the presence of microvascular disease; hTmn - hyperemic mean transit time; Pd - mean distal coronary pressure.

Table 3. Public Reporting of Coronary Physiology Uptake [38]

\begin{tabular}{lcccccc}
\hline Country & Year & PW & PCI & PW/PCI & Temporal change & Hospital-level reporting? \\
\hline Sweden [39] & 2017 & NR & NR & $26 \%$ & 3.1-fold in 10 years & Yes \\
United Kingdom [40] & 2016 & 18,811 & 100,483 & $19 \%$ & 3.5 -fold in 8 years & Yes \\
Italy [41] & 2016 & 11,000 & 218,751 & $5 \%$ & 1 -4-fold in 4 years & Yes \\
Europe EAPCl [42] & 2015 & NR & 889,957 & $16 \%$ & 2-fold in 5 years & Per country \\
United States [43] & 2014 & $3,465^{*}$ & NR & $31 \%$ & 3.8 -fold in 5 years & No \\
Australia [44] & 2015 & NR & 3,869 & $19 \%$ & 100 -fold in 9 years & Per state \\
\hline
\end{tabular}

* Limited to a subset of the 59,375 patients in the National Cardiovascular Data Registry CathPCI Registry with lesions deemed $40-70 \%$ by visual assessment. EAPCI - European Association of Percutaneous Cardiovascular Interventions; $\mathrm{NR}$ - not reported; PCI - percutaneous coronary intervention; PW - intracoronary pressure wire

pressure across a stenosis recorded by Gruentzig et al. [36] during his initial PCI. Despite this early introduction, the practical use of coronary physiology in the cardiac catheterization laboratory started only in the late 1990's. FFR was first described by Pijls et al. [37] in 1993 and has been evaluated since then in numerous large randomized trials and realworld registries. Tracking the uptake of coronary physiology by dividing the number of pressure wires by the number of PCI's (albeit an imperfect metric) demonstrates an enormous growth in many parts of the world, including some APAC countries [38], as detailed in Table 3 [39-44].

\section{Barriers for adoption of invasive physiologic assessment in a cardiac catheterization laboratory}

Despite clear evidence and guideline recommendations, many interventional cardiologists continue to rely on visual assessment of stenosis severity alone rather than using physiologic assessment in a cardiac catheterization laboratory. Multiple reasons have been attributed to the differential use of physiology-guided PCI. These factors include:

- logistics;

- cost;

- availability of hyperaemic agents;

- extra-time for physiologic assessment;

- concerns regarding potential complications;

- uncertainty about optimal performance of physiology assessment;

- relying on invasive imaging assessment;

- interpretation of FFR measurements, particularly in complex situations, such as multi-vessel disease, left main disease, serial lesions, and patients with coronary artery bypass grafts.

Although intracoronary pressure assessment is not technologically challenging to perform, sev- 
eral aspects were suggested to guarantee precise measurements: nitrate administration, proper wire position to avoid artefact, flushing and guide control to avoid damping or ventricularisation, and a postprocedure drift check.

An important issue raised during the meeting was the cost and availability of different hyperaemic agents. Although the intravenous infusion of adenosine/ATP (140 $\mu \mathrm{g} / \mathrm{kg} / \mathrm{min})$ is generally regarded as a gold standard hyperemic method, the use and availability of various hyperaemic agents differs among APAC regions. In Korea and Japan, the use of intracoronary nicorandil ( $2 \mathrm{mg}$ bolus) and papaverine have become popular in clinical practice due to its safety, ease of use, and relatively long-acting effects $[7,8]$.

\section{Recommendations that can increase coronary physiology uptake in APAC countries (5E Approach)}

\section{Evidence}

Since most of the large randomized study data has been generated in Western countries, there is a clear need to generate local APAC real-world data. This could be either in the form of decisionmaking strategy trials like RIPCORD, or in-country large registries like SCAAR (Sweden). Several groups of APAC countries recently published the results of important physiologic studies and those study results from APAC need to be highlighted $[19,26,45-50]$. The group also felt that in-country registry data can provide good scientific evidence to respective health authorities to incorporate invasive physiology in guidelines and reimbursement. Cost effectiveness and clinical outcomes should be an integral part of such a platform. There may also be the potential of conducting 'recovery audits' of catheterization laboratories, just like those done in the United States.

\section{Education}

Education will play a significant role in establishing physiology-guided PCI as a standard practice. There was unanimous agreement to focus on younger interventional cardiologists and fellows and ensure that they are aware of the benefits of physiologic assessment. While this may be a challenge given the lack of learning opportunities in an individual hospital or center, academic societies and industry can play an important role in imparting education at an early stage in their careers. This can be achieved through scientific agenda at important conferences, demonstration through live cases, expert tours etc. Involvement of cardiac catheterization laboratory technicians and nurses will also be crucial to the success of any physiology education program. They are important stakeholders in the entire process and need to be included in the education strategy. The group also felt that it is extremely important to establish patient awareness of physiology-guided PCI. In different healthcare systems in APAC, given the varying reimbursement structures, patient awareness efforts will play a key role in driving benefits of physiologic assessment. The group recommended a dedicated patient-centric approach that can address the potential harm of 'over-stenting'.

\section{Expand capital penetration}

Though a limited role exists for interventional cardiologists in improving product availability, the group recommended developing the infrastructure at small/medium centers, rather than just focusing on high volume centers. Sometimes large volume PCI centres may not fully understand the implications of such a technology and would be resistant to bring about any change in the existing set-up. Smaller volume hospitals tend to invest more in newer technology to continuously upgrade their infrastructure and quality of outcomes.

\section{Economics}

The group strongly felt that health economics would be one of the most important factors to impact the adoption of physiology-guided PCI. There is a strong need to establish the cost effectiveness of the therapy through local registries as the bulk of the evidence has been generated in Western healthcare systems which are structured very differently than APAC healthcare. Positive health economy data will support reimbursement and, in turn, the utility of the therapy.

\section{Expert consensus}

There is growing clinical evidence for the value of coronary physiologic assessment and its beneficial effect on outcomes of coronary interventional procedures for patients. However, a common misconception among interventional cardiologists is that physiology may have a negative impact on the advancements of PCI procedures. Some interventional cardiologists believe that with increasing physiology-guided PCI, the number of overall PCI procedures will come down and this will discourage the value of the PCI procedures, and, as such, prefer stenting over physiologic assessment. There is also a perception that the ad- 
dition of physiological measurements would lead to more time spent in the cardiac catheterization laboratory. In the absence of in-country guidelines or appropriate use criteria in most APAC countries, interventional cardiologists have been inconsistent in their approach to physiologic assessment. Lack of equipment for physiologic assessment and reimbursement in most APAC countries limits such procedures. Though health authorities in some countries have already started to develop guidelines around invasive physiologic assessment and considering reimbursement, there is still a long way to go before it becomes a part of the routine treatment protocol.

\section{Conclusions}

This consensus document and recommendations supports interventional fellows and cardiologists, hospital administrators, patients, and medical device companies to build confidence and encourage wider implementation of the invasive coronary physiology-guided therapy in the APAC region. More consensus meetings and targeted education are needed to guide the proper use of invasive physiologic assessment in the APAC region.

\section{Conflict of interest: None declared}

\section{References}

1. Topol EJ, Nissen SE. Our preoccupation with coronary luminology. The dissociation between clinical and angiographic findings in ischemic heart disease. Circulation. 1995; 92(8): 2333-2342, indexed in Pubmed: 7554219.

2. Yamagishi M, Hosokawa H, Saito S, et al. Coronary disease morphology and distribution determined by quantitative angiography and intravascular ultrasound--re-evaluation in a cooperative multicenter intravascular ultrasound study (COMIUS). Circ J. 2002; 66(8): 735-740, indexed in Pubmed: 12197597.

3. Toth G, Hamilos M, Pyxaras S, et al. Evolving concepts of angiogram: fractional flow reserve discordances in 4000 coronary stenoses. Eur Heart J. 2014; 35(40): 2831-2838, doi: 10.1093/ eurheartj/ehu094, indexed in Pubmed: 24644308.

4. Pijls NH, Van Gelder B, Van der Voort P, et al. Fractional flow reserve. A useful index to evaluate the influence of an epicardial coronary stenosis on myocardial blood flow. Circulation. 1995; 92(11): 3183-3193, indexed in Pubmed: 7586302.

5. Toth GG, Toth B, De Vroey F, et al. Revascularization decisions in patients with stable angina and intermediate lesions: results of the international survey on interventional strategy. Circ Cardiovasc Interv. 2014; 7(6): 751-759, doi: 10.1161/CIRCINTERVENTIONS.114.001608, indexed in Pubmed: 25336468.

6. Zaleska M, Kołtowski $€$, Maksym J, et al. Alternative methods for functional assessment of intermediate coronary lesions. Cardiol J. 2019 [Epub ahead of print], doi: 10.5603/CJ.a2019.0027, indexed in Pubmed: 30912574.
7. Lee JM, Kato D, Oi M, et al. Safety and efficacy of intracoronary nicorandil as hyperaemic agent for invasive physiological assessment: a patient-level pooled analysis. EuroIntervention. 2016; 12(2): e208-e215, doi: 10.4244/EIJV12I2A34, indexed in Pubmed: 27290680.

8. Jang HJ, Koo BK, Lee HS, et al. Safety and efficacy of a novel hyperaemic agent, intracoronary nicorandil, for invasive physiological assessments in the cardiac catheterization laboratory. Eur Heart J. 2013; 34(27): 2055-2062, doi: 10.1093/eurheartj/ eht040, indexed in Pubmed: 23396491.

9. Neumann FJ, Sousa-Uva M, Ahlsson A, et al. Considerations for the choice between coronary artery bypass grafting and percutaneous coronary intervention as revascularization strategies in major categories of patients with stable multivessel coronary artery disease: an accompanying article of the task force of the $2018 \mathrm{ESC} / \mathrm{EACTS}$ guidelines on myocardial revascularization. Eur Heart J. 2019; 40(2): 204-212, doi: 10.1093/eurheartj/ ehy532, indexed in Pubmed: 30165435.

10. Fihn SD, Blankenship JC, Alexander KP, et al. American College of Cardiology/Americal Heart Association Task Force on Practice Guidelines, American Association for Thoracic Surgery, Preventive Cardiovascular Nurses Association, Society for Cardiovascular Angiography and Interventions, Society of Thoracic Surgeons. 2014 ACC/AHA/AATS/PCNA/SCAI/STS focused update of the guideline for the diagnosis and management of patients with stable ischemic heart disease: a report of the American College of Cardiology/American Heart Association Task Force on Practice Guidelines, and the American Association for Thoracic Surgery, Preventive Cardiovascular Nurses Association, Society for Cardiovascular Angiography and Interventions, and Society of Thoracic Surgeons. J Thorac Cardiovasc Surg. 2015; 149(3): e5-23, doi: 10.1016/j.jtcvs.2014.11.002, indexed in Pubmed: 25827388.

11. Lachance P, Déry JP, Rodés-Cabau J, et al. Impact of fractional flow reserve measurement on the clinical management of patients with coronary artery disease evaluated with noninvasive stress tests prior to cardiac catheterization. Cardiovasc Revasc Med. 2008; 9(4): 229-234, doi: 10.1016/j.carrev.2008.02.002, indexed in Pubmed: 18928947.

12. Van Belle E, Gil R, Klauss V, et al. Impact of routine invasive physiology at Time of angiography in patients with multivessel coronary artery disease on reclassification of revascularization strategy: results from the DEFINE REAL study. JACC Cardiovasc Interv. 2018; 11(4): 354-365, doi: 10.1016/j.jcin.2017.11.030, indexed in Pubmed: 29471949.

13. Van Belle E, Baptista SB, Raposo L, et al. Impact of Routine Fractional Flow Reserve on Management Decision and 1-Year Clinical Outcome of Patients With Acute Coronary Syndromes: PRIME-FFR (Insights From the POST-IT [Portuguese Study on the Evaluation of FFR-Guided Treatment of Coronary Disease] and R3F [French FFR Registry] Integrated Multicenter Registries - Implementation of FFR [Fractional Flow Reserve] in Routine Practice). Circ Cardiovasc Interv. 2017; 10(6), doi: 10.1161/CIRCINTERVENTIONS.116.004296, indexed in Pubmed: 28615234.

14. Layland J, Oldroyd KG, Curzen N, et al. Fractional flow reserve vs. angiography in guiding management to optimize outcomes in non-ST-segment elevation myocardial infarction: the British Heart Foundation FAMOUS-NSTEMI randomized trial. Eur Heart J. 2015; 36(2): 100-111, doi: 10.1093/eurheartj/ehu338, indexed in Pubmed: 25179764. 
15. Nakamura M, Yamagishi M, Ueno T, et al. Modification of treatment strategy after FFR measurement: CVIT-DEFER registry. Cardiovasc Interv Ther. 2015; 30(1): 12-21, doi: 10.1007/s12928014-0266-4, indexed in Pubmed: 24816634.

16. Van Belle E, Rioufol G, Pouillot C, et al. Outcome impact of coronary revascularization strategy reclassification with fractional flow reserve at time of diagnostic angiography: insights from a large French multicenter fractional flow reserve registry. Circulation. 2014; 129(2): 173-185, doi: 10.1161/CIRCULATIONAHA.113.006646, indexed in Pubmed: 24255062.

17. Curzen N, Rana O, Nicholas Z, et al. Does routine pressure wire assessment influence management strategy at coronary angiography for diagnosis of chest pain?: the RIPCORD study. Circ Cardiovasc Interv. 2014; 7(2): 248-255, doi: 10.1161/CIRCINTERVENTIONS.113.000978, indexed in Pubmed: 24642999.

18. Zimmermann FM, Ferrara A, Johnson NP, et al. Deferral vs. performance of percutaneous coronary intervention of functionally non-significant coronary stenosis: 15 -year follow-up of the DEFER trial. Eur Heart J. 2015; 36(45): 3182-3188, doi: 10.1093/ eurheartj/ehv452, indexed in Pubmed: 26400825.

19. Park SH, Jeon KH, Lee JM, et al. Long-Term Clinical Outcomes of Fractional Flow Reserve-Guided Versus Routine Drug-Eluting Stent Implantation in Patients With Intermediate Coronary Stenosis: Five-Year Clinical Outcomes of DEFER-DES Trial. Circ Cardiovasc Interv. 2015; 8(12): e002442, doi: 10.1161/CIRCINTERVENTIONS.115.002442, indexed in Pubmed: 26643736.

20. van Nunen LX, Zimmermann FM, Tonino PAL, et al. Fractional flow reserve versus angiography for guidance of $\mathrm{PCI}$ in patients with multivessel coronary artery disease (FAME): 5-year followup of a randomised controlled trial. Lancet. 2015; 386(10006): 1853-1860, doi: 10.1016/S0140-6736(15)00057-4, indexed in Pubmed: 26333474.

21. Xaplanteris P, Fournier S, Pijls NHJ, et al. Five-Year Outcomes with PCI Guided by Fractional Flow Reserve. N Engl J Med. 2018; 379(3): 250-259, doi: 10.1056/NEJMoa1803538, indexed in Pubmed: 29785878.

22. Smits PC, Abdel-Wahab M, Neumann FJ, et al. Fractional flow reserve-guided multivessel angioplasty in myocardial infarction. N Engl J Med. 2017; 376(13): 1234-1244, doi: 10.1056/NEJMoa1701067, indexed in Pubmed: 28317428.

23. Engstrøm T, Kelbæk H, Helqvist S, et al. Complete revascularisation versus treatment of the culprit lesion only in patients with ST-segment elevation myocardial infarction and multivessel disease (DANAMI-3-PRIMULTI): an open-label, randomised controlled trial. Lancet. 2015; 386(9994): 665-671, indexed in Pubmed: 26347918.

24. Davies JE, Sen S, Dehbi HM, et al. Use of the Instantaneous Wave-free Ratio or Fractional Flow Reserve in PCI. N Engl J Med. 2017; 376: 1824-1834.

25. Götberg M, Christiansen EH, Gudmundsdottir IJ, et al. Instantaneous Wave-free Ratio versus Fractional Flow Reserve to Guide PCI. N Engl J Med. 2017; 376(19): 1813-1823, doi: 10.1056/ NEJMoa1616540, indexed in Pubmed: 28317438.

26. Lee JM, Hwang D, Park J, et al. Exploring coronary circulatory response to stenosis and its association with invasive physiologic indexes using absolute myocardial blood flow and coronary pressure. Circulation. 2017; 136(19): 1798-1808, doi: 10.1161/CIRCULATIONAHA.117.029911, indexed in Pubmed: 28851731.

27. Lee JM, Park J, Hwang D, et al. Similarity and Difference of Resting Distal to Aortic Coronary Pressure and Instantaneous Wave-Free Ratio. J Am Coll Cardiol. 2017; 70(17): 2114-2123, doi: 10.1016/j.jacc.2017.09.007, indexed in Pubmed: 29050558.
28. Lee JM, Doh JH, Nam CW, et al. Functional approach for coronary artery disease: filling the gap between evidence and practice. Korean Circ J. 2018; 48(3): 179-190, doi: 10.4070/kcj.2017.0393, indexed in Pubmed: 29557104.

29. Lee J, Shin ES, Nam CW, et al. Clinical outcomes according to fractional flow reserve or instantaneous wave-free ratio in deferred lesions. JACC: Cardiovasc Interv. 2017; 10(24): 2502 2510, doi: 10.1016/j.jcin.2017.07.019.

30. Lee JM, Shin ES, Nam CW, et al. Discrepancy between fractional flow reserve and instantaneous wave-free ratio: Clinical and angiographic characteristics. Int J Cardiol. 2017; 245: 63-68, doi: 10.1016/j.ijcard.2017.07.099, indexed in Pubmed: 28789845.

31. Lee JM, Hwang D, Park J, et al. Physiologic mechanism of discordance between instantaneous wave-free ratio and fractional flow reserve: Insight from N-ammonium positron emission tomography. Int J Cardiol. 2017; 243: 91-94, doi: 10.1016/j.ijcard.2017.05.114, indexed in Pubmed: 28600102.

32. Van't Veer M, Pijls NHJ, Hennigan B, et al. Comparison of Different Diastolic Resting Indexes to iFR: Are They All Equal? J Am Coll Cardiol. 2017; 70(25): 3088-3096, doi: 10.1016/j. jacc.2017.10.066, indexed in Pubmed: 29268922.

33. Svanerud J, Ahn JM, Jeremias A, et al. Validation of a novel nonhyperaemic index of coronary artery stenosis severity: the Resting Full-cycle Ratio (VALIDATE RFR) study. EuroIntervention. 2018; 14(7): 806-814, doi: 10.4244/EIJ-D-18-00342, indexed in Pubmed: 29790478.

34. Lee JM, Layland J, Jung JH, et al. Integrated physiologic assessment of ischemic heart disease in real-world practice using index of microcirculatory resistance and fractional flow reserve: insights from the International Index of Microcirculatory Resistance Registry. Circ Cardiovasc Interv. 2015; 8(11): e002857, doi: 10.1161/CIRCINTERVENTIONS.115.002857, indexed in Pubmed: 26499500.

35. Lee JM, Jung JH, Hwang D, et al. Coronary flow reserve and microcirculatory resistance in patients with intermediate coronary stenosis. J Am Coll Cardiol. 2016; 67(10): 1158-1169, doi: 10.1016/j.jacc.2015.12.053, indexed in Pubmed: 26965536.

36. Grüntzig AR, Senning A, Siegenthaler WE. Nonoperative dilatation of coronary-artery stenosis: percutaneous transluminal coronary angioplasty. N Engl J Med. 1979; 301(2): 61-68, doi: 10.1056/ NEJM197907123010201, indexed in Pubmed: 449946.

37. Pijls NH, van Son JA, Kirkeeide RL, et al. Experimental basis of determining maximum coronary, myocardial, and collateral blood flow by pressure measurements for assessing functional stenosis severity before and after percutaneous transluminal coronary angioplasty. Circulation. 1993; 87(4): 1354-1367, indexed in Pubmed: 8462157.

38. Johnson NP, Koo BK. Coronary psychology: do you believe? JACC Cardiovasc Interv. 2018; 11(15): 1492-1494, doi: 10.1016/j. jcin.2018.05.021, indexed in Pubmed: 30093054.

39. SWEDEHEART Annual Report. 2017.

40. BCIS Audit Slide Deck. 2016.

41. Dati di attività dei Laboratori di Emodinamica. 2016.

42. Barbato E, Dudek D, Baumbach A, et al. Current trends in coronary interventions: an overview from the EAPCI registries. EuroIntervention. 2017; 13(Z): Z8-Z10, doi: 10.4244/eijv13iza2.

43. Desai NR, Bradley SM, Parzynski CS, et al. Appropriate Use Criteria for Coronary Revascularization and Trends in Utilization, Patient Selection, and Appropriateness of Percutaneous Coronary Intervention. JAMA. 2015; 314(19): 2045-2053, doi: 10.1001/jama.2015.13764, indexed in Pubmed: 26551163. 
44. May AN, Kull A, Gunalingam B, et al. The uptake of coronary fractional flow reserve in Australia in the past decade. Med J Aust. 2016; 205(3): 127, indexed in Pubmed: 27465768.

45. Koo BK, Kang HJ, Youn TJ, et al. Physiologic assessment of jailed side branch lesions using fractional flow reserve. J Am Coll Cardiol. 2005; 46(4): 633-637, doi: 10.1016/j.jacc.2005.04.054, indexed in Pubmed: 16098427.

46. Koo BK, Park KW, Kang HJ, et al. Physiological evaluation of the provisional side-branch intervention strategy for bifurcation lesions using fractional flow reserve. Eur Heart J. 2008; 29(6): 726-732, doi: 10.1093/eurheartj/ehn045, indexed in Pubmed: 18308689 .

47. Ahn JM, Park DW, Shin ES, et al. Fractional flow reserve and cardiac events in coronary artery disease: data from a prospective IRIS-FFR registry (interventional cardiology research incooperation society fractional flow reserve). Circulation. 2017; 135(23):
2241-2251, doi: 10.1161/CIRCULATIONAHA.116.024433, indexed in Pubmed: 28356440.

48. Lee JM, Koo BK, Shin ES, et al. Clinical implications of threevessel fractional flow reserve measurement in patients with coronary artery disease. Eur Heart J. 2018; 39(11): 945-951, doi: 10.1093/eurheartj/ehx458, indexed in Pubmed: 29020260.

49. Chen SL, Zhang JJ, Han Y, et al. Double Kissing Crush Versus Provisional Stenting for Left Main Distal Bifurcation Lesions: DKCRUSHV Randomized Trial. J Am Coll Cardiol. 2017; 70(21): 2605-2617, doi: 10.1016/j.jacc.2017.09.1066, indexed in Pubmed: 29096915.

50. Li SJ, Ge Z, Kan J, et al. Cutoff value and long-term prediction of Clinical events by FFR measured immediately after implantation of a drug-eluting stent in patients with coronary artery disease: 1- to 3-year results from the DKCRUSH VII registry study. JACC Cardiovasc Interv. 2017; 10(10): 986-995, doi: 10.1016/j. jcin.2017.02.012, indexed in Pubmed: 28456699. 